\title{
THE
}

\section{Implementing Reverse Mentoring to Address Social Isolation Among Older Adults}

\author{
Bethany M. Breck \\ Cory B. Dennis \\ Skye N. Leedahl \\ University of Rhode Island, skyeleedahl@uri.edu
}

Follow this and additional works at: https://digitalcommons.uri.edu/hdf_facpubs

\section{The University of Rhode Island Faculty have made this article openly available.}

Please let us know how Open Access to this research benefits you.

This is a pre-publication author manuscript of the final, published article.

Terms of Use

This article is made available under the terms and conditions applicable towards Open Access Policy Articles, as set forth in our Terms of Use.

\section{Citation/Publisher Attribution}

Bethany M. Breck, Cory B. Dennis \& Skye N. Leedahl (2018) Implementing reverse mentoring to address social isolation among older adults, Journal of Gerontological Social Work, DOI: 10.1080/ 01634372.2018.1448030

Available at: http://dx.doi.org/10.1080/01634372.2018.1448030

This Article is brought to you for free and open access by the Human Development and Family Science at DigitalCommons@URI. It has been accepted for inclusion in Human Development and Family Science Faculty Publications by an authorized administrator of DigitalCommons@URI. For more information, please contact digitalcommons-group@uri.edu. 


\section{Implementing Reverse Mentoring to Address Social Isolation Among Older Adults \\ Bethany M. Breck, MSW Student \\ Brigham Young University \\ Cory B. Dennis, Ph.D., LCSW \\ Brigham Young University \\ Skye N. Leedahl, Ph.D. \\ University of Rhode Island}

Author Note

Bethany M. Breck, Department of Social Work, Brigham Young University.

Cory B. Dennis, Department of Social Work, Brigham Young University. Skye N. Leedahl, Department of Human Development \& Family Studies, University of Rhode Island.

Correspondence regarding this article should be addressed to Bethany Breck, Department of Social Work, Brigham Young University, 2190 JFSB, Provo UT 84602.

Contact: bethanymbreck@gmail.com 


\title{
Implementing Reverse Mentoring to Address Social Isolation Among Older Adults
}

\begin{abstract}
Reverse mentoring is a means to address the social work Grand Challenge of social isolation. Among older adults, reverse mentoring can improve social connection by increasing the digital competence of older adults so they can use technology for social benefit, and by facilitating intergenerational connections with young adult mentors. In this article, reverse mentoring is examined within an intergenerational program that serves older adults and utilizes the native technological knowledge and skills of young adults who mentor older adult participants. Qualitative data were collected through young adult mentor logs of each session, and through open-ended questions on the post surveys collected from older adults and young adult mentors. Qualitative analysis revealed three themes related to social connection: (1) an increased sense of self-efficacy for older adults as they build confidence in technological use, and for young adults as they develop leadership skills through mentoring; (2) the breaking down of age-related stereotypes; (3) intergenerational engagement and connection. The findings demonstrate that reverse mentoring can be used in various settings to decrease the social isolation of older adults by developing intergenerational connections and increasing older adult usage of technology. Keywords: reverse mentoring, intergenerational program, social isolation, technology, digital engagement
\end{abstract}




\section{Implementing Reverse Mentoring to Address Social Isolation Among Older Adults}

The social work field recently identified social isolation as one of its Grand Challenges to address (Lubben, Gironda, Sabbath, Kong, \& Johnson, 2015). An estimated 17\% of older adults are socially or geographically isolated (Ortiz, 2011). To capture the multiple dimensions of isolation, AARP Foundation (2012, p. 11-12) proposed what they call a "unifying definition of isolation:"

"Isolation is the experience of diminished social connectedness stemming from a process whereby the impact of risk factors outweighs the impact of any existing protective factors. A person's lack of social connectedness is measured by the quality, type, frequency, and emotional satisfaction of social ties. Social isolation can impact health and quality of life, measured by an individual's physical, social, and psychological health; ability and motivation to access adequate support for themselves; and the quality of the environment and community in which they live."

Many factors at the micro, mezzo, and macro levels can place older adults at risk for social isolation and its negative consequences (AARP Foundation, 2012). However, technological advancements present interesting opportunities for responding to and protecting against isolation among older adults.

The term digital divide denotes a gap between those who have and do not have access to computers and the internet (Tetsi, 2017; Van Dijk, 2006). For this paper, we extend digital divide to also denote a gap between those who have the experience and digital literacy necessary to utilize and participate in the digital world and those who do not. Computer anxiety is an obstacle to digital literacy among some older adults--particularly when contrasted with their younger counterparts (Laguna \& Babcock, 1997). While Czaja and colleagues (2006) have shown that 
technology plays a significant role in many aspects of everyday life, making digital literacy increasingly important, Charness, Schumann, and Boritz (2002) found that compared to younger populations, older adults have increased difficulty learning and using technology. However, research has shown an older adults' anxiety towards technology use is mitigated as they receive technological training from others (Czaja et al., 2006), which aligns with the position that digital competence has more to do with exposure to and education about the digital world (Helpser \& Enyon, 2010).

Training older adults in the use of social media has potential to connect older adults to a meaningful network of people and information. Having a native technological skill set that comes with being raised in a world where technology is part of everyday life (Brown \& Czerniewicz, 2010), younger adults are well positioned to train older adults in the use of social media and the internet in general. Research has indicated that social ties for internet users are more than $20 \%$ higher than for non-internet users (Hampton, Goulet, Rainie, \& Purcell, 2011). Although some might fear that internet-based relationships are less meaningful, researchers have reported that internet platforms, such as Facebook, support rather than undermine close friendships (Hampton et al., 2011). Despite its potential, only 9\% of active Facebook users are age 55 and older, with this age group having an even lower presence on other platforms such as YouTube (7\%) and Twitter (6\%) (Global Web Index, 2014). Enlisting younger adults to mentor older adults on using the internet for social gain is beneficial in two ways. First, older adults can connect socially in the short-term by engaging with a young adult mentor as they learn more about ways to use the internet for social benefit. Second, older adults can improve their social connectedness in the long-term by using the internet with greater comfort and ease.

\section{Reverse Mentoring}


Intergenerational models have long addressed many needs of older adults (Teater, 2016).

Reverse mentoring is an intergenerational approach that engages young adults in providing needed support and knowledge to older adults. The concept of reverse mentoring originated in the business sector where top managers were expected to enlist younger employees to mentor them about the internet (Greengard, 2002). This approach continues to be used in business as an innovative and cost-effective professional development tool to help older workers to gain technological skills or generational perspectives to increase their effectiveness (Murphy, 2012). Reverse mentoring aligns well with sociological demographic changes occurring in the workforce because many baby boomers lack the digital expertise of younger generations who grew up in a technology-infused world and who use technology frequently (Chaudhuri \& Ghosh, 2012).

While reverse mentoring flips the typical pedagogy model so that younger adults become the mentor and older adults the mentees (Baily, 2009), younger and older adults both benefit. Reverse mentoring encourages mutual support through knowledge sharing as older adults share their life experiences while gaining new technological skills for digital literacy from younger adults, and it encourages mutual support through positive feedback (Spreitzer, 2006). Young adults benefit in their mentoring role by developing the leadership skills (Murphy, 2012), they need in this digital age (Johnson, 2009). Reverse mentoring addresses social isolation as young adults use their expertise to teach to older adults technological skills that can improve their social connectedness. Yet, reverse mentoring is seldom used to its potential for bringing together and empowering younger and older adults (Baily, 2009). Reverse mentoring is practical for addressing social isolation among older adults by drawing from the talents and ideas of young 
adults, bridging generational leadership differences (Meister \& Willyerd, 2010; Sessa, Kabacoff, Deal, \& Brown, 2007), and exchanging knowledge (Murphy, 2012).

The perspectives of older adults and young adult mentors can further our understanding of how a reverse mentoring program might improve the social well-being of its participants. To explore their perspectives, we used qualitative data to address the following questions: (1) what was the experience among older adults in having younger adults mentor them on technology use for social engagement; (2) what are the social benefits of interacting across generations in a reverse mentoring program. Using qualitative data to understand the perspectives of participants in a reverse mentoring program can produce valuable insights that social workers can use to build and refine reverse mentoring programs, and can inform social work researchers in their development of hypotheses related to testing the effects of reverse mentoring on social isolation and other outcomes (Thyer, 2012).

\section{Method}

\section{Program}

During Spring 2016 semester, the Cyber-Seniors Program connected young adult mentors from multiple departments to older adults living in the community. Young adult mentors helped older adults learn to use their technological devices while gaining skills in teaching and working with older adults. Some young adult mentors held sessions each week at a local senior center or at the Osher Lifelong Learning Institute where older adults would sign up or drop by for assistance during selected times each week that the young adult mentors were available. Some young adult mentors took part in a university class that matched older adults with each young adult mentor, and the matches would meet at agreed upon times and locations. Older adults were 
recruited to the program through signs and newsletter posts. See Leedahl et al., 2018 for full details on the program design and implementation.

\section{Participants}

During the Spring 2016 semester, the program included 87 older adults, 37 of which completed at least three sessions with the program (for a total of 243 sessions with young adult mentors). Further, 29 completed a post-survey $(M$ age $=73.45, S D=5.98)$, which was a $78.4 \%$ response rate. Those who did not complete a post-survey chose not to do so due to time constraints or privacy concerns. To ensure adequate informed consent, we did not require survey participation. Additionally, 28 young adult mentors participated in the program from five different majors across campus (Human Development \& Family Studies, Pharmacy, Health Studies, Communicative Disorders, Psychology). Twenty-six of the young adult mentors completed the post survey $(M$ age $=21.81, S D=2.03)$ for a $92.8 \%$ response rate. The young adult mentors provided approximately 289 hours of service.

\section{Procedure}

Research team members gathered qualitative data from young adult mentors and older adults who took part in the Cyber-Seniors program during Spring 2016. All methods were IRBapproved using the exempt review process (due to minimal risk to participants), and all participants provided informed consent. To gather qualitative data, each young adult mentor answered a set of open-ended questions after each of their sessions with older adults. They wrote about who they met with, what they focused on during each session, what types of questions were brought up, what techniques they used, and how they connected with each person. This information was used to track participation, identify best practices and challenges, 
and examine technology needs and how young adult mentors and older adults connected to one another.

Young adult mentors were also provided a pre-survey prior to participation in the program and a post-survey after finishing their agreed upon hours. For qualitative data, they answered some open-ended questions on the post-survey, which included: (1) Why would or wouldn't you recommend the Cyber-Seniors program?; (2) What was it like teaching older adults how to use technology?; (3) In being a student mentor for the Cyber-Seniors program, what was the most memorable experience?; (4) What was the most significant thing you learned during this program?; (5) What would you like to see included to help improve student experiences in the program?

All older adults completed a pre-survey prior to their first meeting with the young adult mentors, and all older adults who participated in at least three hours with the program completed a post-survey. The post-survey included open-ended questions, which enabled us to collect qualitative data. These questions were: (1) Why would or wouldn't you recommend the CyberSeniors program?; (2) What was your favorite part of the program?; (3) What was the most valuable thing you learned in this program?; (4) Has the program changed how you use technology? If so, how?; (5) What would you like to see included or improved in future CyberSeniors programs?; (6) Any final comments, questions, or feedback?

\section{Analysis}

The qualitative data were analyzed using a phenomenological approach (Patton, 2015), meaning the researchers analyzed the data to understand older adults' and young adult mentors' perceptions of their experience in the program. We began by using an open coding process, in which we utilized inductive analysis to discover themes that emerged from the data. Once these 
themes were established, we utilized deductive analysis to affirm the initial themes found in the data. Finally, we identified themes that pertained to our overall focus on reverse mentoring (Patton, 2015). The units of text that were coded in this study were sentences from the 250 pages of text.

A two-person team identified an initial list of codes after reading through approximately 250 pages of text. The initial list of codes included: humorous \& fun; family purchase; personal bond \& relationship; negative emotions; open-minded; comfortable; appreciative (student mentors \& older adults towards one another); excited and enthusiastic; eager to learn; improvements (skills); patience; families (children, grandchildren, great-grandchildren); interactions; organized (student mentors planned ahead). After identifying this initial code list, two other researchers read through the data and coded it based on the list of codes and their definitions and added additional codes when new ideas not on the initial list were identified. To ensure agreement across coders, the research team leaders read through the codes to establish that words marked matched the codes and their definitions.

After going through this open coding process, the lead author subsumed the codes into the following higher-level themes: personal bond \& relationship; open-minded; improvements (skills); patience; organization; and interactions. For this article, we focused on presenting information that pertains to reverse mentoring from these categories, and we identified the themes presented in this article from information identified in the literature about the value of reverse mentoring (Murphy, 2012). A 93.1\% agreement was reached by the lead author and the lead researcher for the final coding of the themes presented in this article.

\section{Results}


Older adult participants and young adult mentors observed benefits from participating in the Cyber-Seniors program. Three recurring themes on the value of reverse mentoring as it relates to alleviating social isolation for older adults emerged from the data: (1) the increase of self-efficacy found in both young adult mentors and older adult participants, (2) the breaking down of generational stereotypes, and (3) the connectivity found through intergenerational bonds formed between young adult mentors and older adult participants.

\section{Self-Efficacy}

Both the younger and older participants expressed various ways in which they developed self-efficacy. Self-efficacy is having the knowledge of how to perform a task, and the experience, initiative, and confidence to complete the task (Bandura, 1982). Young adult mentors reported increasing their self-efficacy by gaining leadership skills through mentoring their older adult partners. Older adults reported gaining confidence in their ability to use technology and engage socially in the digital world. An increase of self-efficacy has long been found to increase the social support of older adults (Holahan \& Holahan, 1987).

Young adult mentors found meaning and value in teaching basic but important technological skills to older adult participants. They found value in their technological expertise that might have been taken for granted because it was seen as too basic:

"I have also noted that teaching something so small can leave a huge impact on them... I mean that something so minimal to me could still have a lasting effect on someone. In [participating older adult]'s case, teaching him how to delete pictures and text messages (so easy to me, [while] difficult for him) easily took a lot of stress off of him." 
Young adult mentors' excitement for and confidence in their ability to teach another person seemingly basic but valuable technological skills seemed to grow. One young adult noted that she gained confidence in mentoring others that would carry over into future situations:

"I firmly believe that I will be able to apply the skills that these seniors have taught me to my future as a pharmacist. Not only will I be stronger in communicating with patients, but I'll also be more patient in myself."

The connection older adult participants felt with their young adult mentors seemed, in part, due to the way young adults approached this reverse mentoring opportunity. Older adult participants commented on feeling empowered and encouraged as they learned technological skills from their young adult mentors and as they connected with their young adult mentors. As one participant stated:

"Having a patient, kindly, knowledgeable teacher has enabled me to not be depressed with these expensive devices I purchased and used only nominally. Now, I feel uplifted about technology and not depressed. It has opened up a new world for me”.

The connection formed between older adult participants and young adult mentors is one way that reverse mentoring addresses isolation. Another way is that feeling empowered and encouraged by their young adult mentors will likely affect older adults' comfort with and ability to use technology to benefit themselves socially.

Involvement in a reverse-mentoring relationship provided a unique and positive opportunity for intergenerational knowledge to be exchanged. Young adult mentors and older adults reported learning from one another, even when young adult mentors were in the primary leadership role. One young adult mentor reported that mentoring older adults provided them with experiential information: 
"This intergenerational program showed me that I have just as much information to learn from older adults as I did to teach them about technology."

Another young adult mentor learned important life lessons, reporting that:

"I have learned from [older adult participant] the importance of lifelong learning. She has made it clear that she is passionate about education and has helped me to continue to be passionate about learning... She has also made it clear how fulfilling a life you live without being married or having a large immediate family. [Older adult participant] has created a network of great friends all over the world... This is proof to me that you don't have to live a 'traditional' life to be fulfilled."

Older adult participants gained confidence in their ability to use technology by participating in the Cyber-Seniors program. Their confidence grew by the young adult mentors' ability to simplify the technology using experience as reported by an older adult who stated that the program, "Helped me feel more confident to use technology. [The] students made it simple." The confidence of older adults grew also because their familiarity with using the internet grew:

"I learned where to find information. [The program] gave me confidence on where to find things on the computer."

The young adult mentors facilitated the growth in the older adults' confidence by mentoring them. Improving the confidence of older adults in using technology through reverse mentoring is one means for decreasing the anxiety older adults might have toward using technology to enhance their social connection.

\section{Breaking Down Generational Stereotypes}

Young adult mentors learned to appreciate the diversity and uniqueness of older adults, challenging the stereotype that they are all the same. One young adult reported that reverse 
mentoring allowed them the opportunity to learn about and connect with the individuality of the older adult they mentored:

"I feel as though this program helps to show that older adults are not all what we think they are... When you have met one older adult, you have met one older adult. Everyone is different and unique in their own way."

Another young adult mentor reported an opened perspective on the societal stereotypes that are prevalent regarding older adults and conveyed a sense of interest in changing the stereotypes that exist:

"I have learned that we should really rethink the way we perceive our older adults in society. Many of them truly do a lot for us, and it is not right for us to stereotype them, just as it is not right to do it to anyone else. [Older adult] supports her community and gives back by volunteering to do budget work at her church, helping run the alumni program at [University], and in other ways. I have learned that older adults are just as needed in our society as younger generations, and we as a whole need to realize this and work on the way we think about them. They should feel just like anyone else in a Community."

Older adult participants expressed initial apprehension about their own lack of experience with technology and their discomfort with learning more about it. Yet, several participants experienced a newfound capacity to learn new technology. As one participant stated at the conclusion of the program, "I can learn this. I am not too old." This perspective demonstrates a willingness to challenge their own negative stereotypes about themselves and their generation regarding learning and utilizing technology. 
The interactions between young adult mentors and older adult participants challenged negative stereotypes in important ways. This was a recurrent theme among participants of the program as noted by one of the young adult mentors:

"Personally, I was very apprehensive about this program because I did not think I liked working with older adults. The relationships I have with the older adults in my life (my grandparents) is very formal and I feel that while we care about each other, there is not much of a bond there... As the program went on I found myself enjoying it a lot more than I thought I would."

While young adult mentors experienced a positive shift in their perception of older adults, older adult participants also experienced a shift in how they view younger adults. Two older adult participants gave insight on how their own stereotypes of younger adults were altered through participation in the program:

"I learn[ed] that there are young people working hard to make their lives better with kindness, compassion, and a sense of humor."

"People of any age can share common interests (particularly with such a large age difference)."

The breakdown of stereotypes allows for interesting and positive interactions to occur across generations. This is one way that reverse mentoring can improve the social connections of older adults.

\section{Intergenerational Connections}

Participating in the Cyber-Seniors program also provided older adult participants an opportunity to connect socially in a direct way. Reverse mentoring facilitates direct intergenerational interactions that were beneficial to younger and older adults participating in 
this study. This is a way that reverse mentoring can address the social isolation that many older adults face. Young adult mentors emphasized the benefit of intergenerational learning and connections such as the following:

"This project is a unique opportunity to share intergenerational thoughts, ideas, experiences, and moments with an elder that you wouldn't know otherwise".

Many young adult mentors reported sharing common values and interests with the older adult they mentored:

"It was a surprise to me that [older adult participant] and I had very similar interests even though there was quite an age difference. Hopefully, more people will participate in [programs] like these, and realize that you may share similar interests and values no matter your age.”

Another young adult mentor reported forming a meaningful relationship with the older adult they mentored:

"We both have been open with communication and it has made the connection easier to form. It has been extremely easy to get to know one another. I think over the past couple of weeks, our ability to be open with each other has made this experience so much better... We honestly enjoy spending this time with each other... We are genuinely excited to meet with each other each week... And I believe that it's entirely because of how naturally the bond has formed."

Many older adult participants experienced similar feelings of appreciation for the opportunity to interact with their young adult mentor. One older adult participant remarked that the best part of the program was:

"Discover[ing] wider connections, increasing my confidence to use technology, and 
meeting my cyber buddy."

Another older adult reported their interaction with their young adult mentor was one of the program's greatest strengths, providing them an opportunity to feel socially connected while learning important technological skills:

"Beyond the technical knowledge learned, speaking with [young adult mentor] was most enjoyable. Linking up with other generations is positive and keeps us all growing." While teaching older adults to use technology holds promise for addressing social isolation, the intergenerational connection they experienced by participating in this reverse mentoring program seemed to prevail for addressing social isolation among older adult participants. Older adult participants and young adult mentors both acknowledged the social benefit of reverse mentoring.

\section{Discussion}

This study found reverse mentoring to have a positive impact on younger and older adults. Older adult participants reported increasing their knowledge of and confidence in using technology for social benefit. Becoming digitally competent might then have less to do with age and more to do with the opportunity to learn, which this reverse mentoring program provided. This matches previous research on digital competence and confidence because exposure to and experience with technology led to an increased sense of confidence in the older adults (Helpser \& Eynon, 2010). While a significant number of older adults are isolated (AARP Foundation, 2012) and less likely to engage digitally (Global Web Index, 2014), reverse mentoring is one approach for helping older adults become socially active through digital engagement.

The results from this study align with previous research showing that reverse mentoring

draws from the talents and ideas of younger people, allows for intergenerational connections, and has the potential to build leadership skills for younger adults (Meister \& Willyerd, 2010; Sessa et 
al., 2007). The reverse mentoring approach used in this study showed similar impact in creating strong intergenerational connections and increased self-efficacy. Additionally, our results demonstrate that by using their technological expertise to educate older adults on ways to use technology to socially connect, young adult mentors increase their sense of self-efficacy in their ability to lead and contribute to improving lives. Our results also show that reverse mentoring has power to challenge age-related stereotypes by building intergenerational connections that enhance the relatability and appreciation older adults and younger adults can have for each other. Reverse mentoring has potential to be instrumental in the field of social work as a programmatic way to address social isolation among older adults, while simultaneously building a more inclusive society.

While reverse mentoring has been used effectively to enhance productivity in the workforce (Greengard, 2002), the results of this study suggest that reverse mentoring is a fitting model for social workers in addressing social isolation among older adults because programs like this can help older adults gain digital competence from the mentoring of young adults who are experts in the use of technology. Reverse mentoring is a path towards increasing older adults' confidence in using technology to connect socially, and for decreasing their social isolation through intergenerational interactions. There are increasing possibilities for reverse mentoring to positively impact older adults and young adult mentors in a variety of social work settings.

By brokering the technological expertise of younger generations, social workers can help improve the social connection and social well-being of older adults who are at risk for social isolation. Younger adults who are familiar with using technology as a means for social connection are well-prepared to mentor older adults on using technology for social benefit (Murphy, 2012). This model also benefits younger adults by placing them in a mentorship role 
where they can develop leadership skills by using their native technological expertise to help others. Reverse mentoring holds promise for improving the social well-being of older adults through technology, and through intergenerational connections and support.

To address the Grand Challenge of social isolation (Lubben et al., 2015) among older adults, we recommend that social work practitioners and policy makers consider implementing reverse mentoring programs to bridge the digital divide towards improving the social connections of older adults. Social isolation among older adults may be alleviated through using reverse mentoring programs to cultivate intergenerational connections and develop the digital competence of older adults so they can connect socially through digital platforms.

While this study provides insight into the experiences of a sample of older adults and young adult mentors participating in a reverse mentoring program, there are several limitations to consider when interpreting the results of this study. For instance, the sampling strategy and sample size limit the generalizability of the results. Further, stereotype threat (Steele \& Aronson, 1995) can affect older adults' performance (Lamont, Swift, \& Abrams, 2015) and might bias the results of this study. Another limitation inherent in qualitative research is that we are unable to claim causation of the intervention on the themes identified among participants (Thyer, 2012). Thus, rather than claim causation, this study provides a phenomenological understanding of how older adults and young adult mentors might experience participating in a reverse mentoring program. To address some of these limitations, we recommend quantitative research that employs sampling designs that can enhance the generalizability of knowledge about the relationship between reverse mentoring and social well-being, and further qualitative research should ensure that intercoder reliability is reached in the open-coding process. We also recommend that researchers from various disciplines use experimental designs to study possible 
causal effects of reverse mentoring models on the social well-being of older adults and young adult mentors and on other psychosocial outcomes. 


\section{References}

AARP Foundation. (2012). Framework for isolation in adults over 50. Retrieved from http://www.aarp.org/content/dam/aarp/aarp_foundation/2012_PDFs/AARP-FoundationIsolation-Framework-Report.pdf

Baily, C. (2009). Reverse intergenerational learning: A missed opportunity?. Ai \& Society, 23(1), 111-115. https://doi.org/10.1007/s00146-007-0169-3

Bandura, A. (1982). Self-efficacy mechanism in human agency. American Psychologist, 37, 122-147. https://doi.org/10.1037/0003-066X.37.2.122

Brown, C., \& Czerniewicz, L. (2010). Debunking the 'digital native': Beyond digital apartheid, towards digital democracy. Journal of Computer Assisted Learning, 26(5), 357-369. https://doi.org/10.1111/j.1365-2729.2010.00369.x

Charness, N., Schumann, C., \& Boritz, G. (2002). Training older adults in word processing: Effects of age, training technique, and computer anxiety. International Journal of Technology and Aging, 5, 79-105.

Chaudhuri, S., \& Ghosh, R. (2012). Reverse mentoring: A social exchange tool for keeping the boomers engaged and millennials committed. Human Resource Development Review, 11(1), 55-76. https://doi.org/10.1177/1534484311417562

Czaja, S. J., Charness, N., Fisk, A. D., Hertzog, C., Nair, S. N., Rogers, W. A., \& Sharit, J. (2006). Factors predicting the use of technology: Findings from the Center for Research and Education on Aging and Technology Enhancement (CREATE). Psychology and Aging, 21, 333-352. https://doi.org/10.1037/0882-7974.21.2.333

Global Web Index. (2014). Age distribution of active social media users worldwide as of 3rd 
quarter 2014, by platform. In Statista - The Statistics Portal. Retrieved on May 18, 2017 from http://insight.globalwebindex.net/social

Greengard, S. (2002). Moving forward with reverse mentoring. Workforce, 81(3), 15-15.

Hampton, K., Goulet, L. S., Rainie, L., \& Purcell, K. (2011). Social networking sites and our lives. Pew Internet \& American Life Project, 16. Retrieved from http://cn.cnstudiodev.com/uploads/document_attachment/attachment/46/pew__social_networking_sites_and_our_lives.pdf

Helsper, E. J., \& Eynon, R. (2010). Digital natives: where is the evidence?. British Educational Research Journal, 36(3), 503-520. https://doi.org/10.1080/01411920902989227

Holahan, C. K., \& Holahan, C. J. (1987). Self-efficacy, social support, and depression in aging: A longitudinal analysis. Journal of Gerontology, 42(1), 65-68. https://doi.org/10.1093/geronj/42.1.65

Johnson, J. L. (2009). The nonprofit leadership deficit: A case for more optimism. Nonprofit Management and Leadership, 19(3), 285-304. https://doi.org/10.1002/nml.220

Laguna, K., \& Babcock, R. L. (1997). Computer anxiety in young and older adults: Implications for human-computer interactions in older populations. Computers in Human Behavior, 13(3), 317-326. https://doi.org/10.1016/S0747-5632(97)00012-5

Lamont, R. A., Swift, H. J., \& Abrams, D. (2015). A review and meta-analysis of age-based stereotype threat: Negative stereotypes, not facts, do the damage. Psychology and Aging, 30(1), 180-193. http://dx.doi.org/10.1037/a0038586

Leedahl, S.N., Brasher, M., Estus, E., Breck, B.M., Dennis, C.B., \& Clark, S.C. (2018). Implementing an interdisciplinary intergenerational program using the Cyber-Seniors ${ }^{\circledR}$ 
reverse mentoring model. Journal of Gerontology \& Geriatrics Education. https://doi.org/10.1080/02701960.2018.1428574

Lubben, J., Gironda, M., Sabbath, E., Kong, J., \& Johnson, C. (2015). Social isolation presents a grand challenge for social work (Grand Challenges for Social Work Initiative Working Paper No. 7). Cleveland, OH: American Academy of Social Work and Social Welfare.

Meister, J. C., \& Willyerd, K. (2010). Mentoring millennials. Harvard Business Review, 88(5), $67-72$.

Murphy, W. (2012). Reverse mentoring at work: Fostering cross-generational learning and developing millennial leaders. Human Resource Management, 51, 549-574. https://doi.org/10.1002/hrm.21489

Ortiz, H. (2011). Crossing new frontiers: Benefits access among isolated seniors. National Center for Benefits Outreach and Enrollment (NCBOE). National Council on Aging. Retrieved from https://www.ncoa.org/wp-content/uploads/crossing-new-frontiers.pdf

Patton, M.Q. (2015). Qualitative research and evaluation methods (4th ed.). Thousand Oaks, CA: Sage.

Sessa, V. I., Kabacoff, R. I., Deal, J., \& Brown, H. (2007). Generational differences in leader values and leadership behaviors. The Psychologist-Manager Journal, 10(1), 47-74. https://doi.org/10.1080/10887150709336612

Spreitzer, G. M. (2006). Leading to grow and growing to lead: Leadership development lessons from positive organizational studies. Organizational Dynamics, 35, 305-315. https://doi.org/10.1016/j.orgdyn.2006.08.005 
Steele, C. M., \& Aronson, J. (1995). Stereotype threat and the intellectual test performance of African Americans. Journal of Personality and Social Psychology, 69(5), 797 811. http://dx.doi.org/10.1037/0022-3514.69.5.797

Teater, B. (2016). Intergenerational Programs to Promote Active Aging: The Experiences and Perspectives of Older Adults. Activities, Adaptation \& Aging, 40(1), 1-19. https://doi.org/10.1080/01924788.2016.1127041

Thyer, B. A. (2012). The scientific value of qualitative research for social work. Qualitative Social Work, 11(2), 115-125. https://doi.org/10.1177/1473325011433928

Tsetsi, E., \& Rains, S. A. (2017). Smartphone Internet access and use: Extending the digital divide and usage gap. Mobile Media \& Communication, https://doi.org/10.1177/2050157917708329

Van Dijk, J. A. (2006). Digital divide research, achievements and shortcomings. Poetics, 34(4-5), 221-235. https://doi.org/10.1016/j.poetic.2006.05.004 